\title{
Drug-Eluting Stents Compared with Bare Metal Stents Improve Late Outcome after Saphenous Vein Graft but Not after Large Native Vessel Interventions
}

\author{
Raban V. Jeger Stefan Schneiter Christoph Kaiser Piero O. Bonetti \\ Hanspeter Brunner-La Rocca Michael Handke Stefan Osswald Peter T. Buser \\ Matthias E. Pfisterer for the BASKET Investigators \\ Department of Cardiology, University Hospital Basel, Basel, Switzerland
}

\section{Key Words \\ Coronary artery bypass grafting • Percutaneous coronary intervention $\cdot$ Stents $\cdot$ Survival $\cdot$ Thrombosis}

\section{Abstract}

Objectives: To define long-term efficacy of different stent types in saphenous vein graft (SVG) interventions. Methods: In BASKET (Basel Stent Cost Effectiveness Trial), major adverse cardiac events (MACE), i.e. cardiac death, myocardial infarction and symptom-driven target vessel revascularization (TVR) were assessed after 18 months comparing drugeluting stents (DES) versus bare metal stents (BMS), and SVG and large native vessels ( $\geq 3.0 \mathrm{~mm}$ ). Results: Large vessel interventions were performed in 605 patients. Patients with SVG interventions ( $n=47,8 \%)$ were older and had more often hypertension, prior myocardial infarction, prior revascularization and multivessel disease and less frequent ST-elevation myocardial infarction than patients with large native vessel interventions ( $n=558,92 \%)$. Stent number and length were higher in SVG than in large native vessel interventions. Baseline characteristics were similar for DES and BMS. In SVG stenting, long-term outcome was better in DES- than in BMS-treated patients (MACE 21 vs. 62\%, $p=0.007$, mainly due to TVR 18 vs. $46 \%, p=0.045$ ), but for large native vessel
\end{abstract}

\section{KARGER}

Fax +41613061234

E-Mail karger@karger.ch

www.karger.com
(C) 2008 S. Karger AG, Basel

0008-6312/09/1121-0049\$26.00/0

Accessible online at:

www.karger.com/crd stenting, no significant difference was noted (MACE: 13 vs. $16 \%, p=0.40$ ). Conclusions: Among patients with SVG disease, treatment with DES resulted in a better long-term outcome than treatment with BMS. In contrast, no DES benefit was found in similarly sized native vessels regarding MACE.

Copyright $\odot 2008$ S. Karger AG, Basel

\section{Introduction}

Interventional revascularization therapy after coronary artery bypass graft (CABG) surgery needs to be performed in 1-2\% of patients per year within the first 5 years after surgery and in $4 \%$ per year subsequently [1]. While atherosclerotic changes leading to severe obstruction or occlusion are present in almost half of all saphenous vein grafts (SVG) after 11 years, the degeneration of these grafts starts early after surgery [1]. Until recently, the standard treatment of SVG atherosclerosis was to repeat CABG [2]. However, angioplasty alone [3-6] and angioplasty with stenting [7-11] have emerged as alternative treatment options in the last years. Thus, treatment of SVG disease currently accounts for about $10 \%$ of all percutaneous coronary interventions (PCI) [12]. Since embolization of friable material was a main problem with 
percutaneous techniques, distal embolic protection [13, 14] and mechanical thrombectomy of large luminal thrombi $[15,16]$ were beneficial regarding short-term major adverse clinical events (MACE), but long-term outcome after PCI of SVG lesions remains poor, primarily due to the high incidence of restenosis and atherosclerotic disease progression $[17,18]$.

In recent years, drug-eluting stents (DES) have shown a proven benefit in reducing intimal hyperplasia and in stent restenosis for selected lesions [19-22], but the safety and efficacy of DES in the treatment of SVG lesions remains unclear. Although recently much concern has been raised regarding the occurrence of late stent thrombosis after DES implantation [23], DES in de novo lesions of large native vessels $\geq 3.0 \mathrm{~mm}$ were beneficial compared with bare metal stents (BMS) in reducing the rate of restenoses $[20,22]$. However, the efficacy of DES in the treatment of SVG lesions has been tested in both nonrandomized [24, 25] and randomized [26, 27] studies. Specifically, the RRISC (Reduction of Restenosis in Saphenous Vein Grafts with Cypher Sirolimus-Eluting Stents) study demonstrated conflicting results with DES reducing late loss after 6 months [26] but exposing to a long-term hazard with increased all-cause mortality after 3 years [27]. In contrast, a previous exploratory analysis of BASKET (Basel Stent Kosten Effektivitäts Trial/Basel Stent Cost Effectiveness Trial) [28] demonstrated that SVG lesions carried a high risk of recurrent clinical events which could be reduced by the use of DES, but specific results were lacking [29].

In light of these results, we used the unselected, realworld patient population of BASKET [28] to define the long-term safety and efficacy of DES in SVG comparing the outcome of patients undergoing PCI of SVG lesions with that of patients undergoing PCI of similarly sized native vessels.

\section{Patients and Methods}

\section{Study Design}

This is a secondary analysis of BASKET as pre-specified in the study protocol. The design of the study has been described previously [28]. In brief, BASKET, a randomized, prospective study, evaluated the cost-effectiveness of two DES, i.e. the sirolimuseluting Cypher ${ }^{\circledR}$ stent (Cordis, Johnson \& Johnson, Miami Lakes, Fla., USA) and the paclitaxel-eluting Taxus ${ }^{\circledR}$ stent (Boston Scientific, Natick, Mass., USA), compared to a 3rd generation cobaltchromium BMS (Vision ${ }^{\circledR}$ stent; Guidant, Indianapolis, Ind., USA). Patients were randomized in a 2:1 fashion to DES and BMS with a 1:1 randomization between the two DES types, and were followed for 18 months. Over 1 year, all patients undergoing PCI at our institution were enrolled in the study; the only exclusion criteria were a vessel diameter $>4 \mathrm{~mm}$ (since the largest DES diameter size available at the time of the study was $3.5 \mathrm{~mm}$ ), restenotic lesions and no consent. The study was approved by the local institutional review board and each patient gave written informed consent.

In a previous analysis of the same dataset, both SVG and vessel size were identified as predictors of late outcome [29]. The present study serves as an exploratory analysis of this finding investigating baseline and outcome differences between SVG and similarly sized native vessels treated with different stent types including all patients with a PCI using a stent $\geq 3 \mathrm{~mm}$ in diameter; however, it was allowed to post-dilate $3.5-\mathrm{mm}$ stents up to $4.0 \mathrm{~mm}$, if necessary. Of note, all SVG interventions up to $4.0-\mathrm{mm}$ vessels were part of this group. The primary endpoint of this analysis was clinically driven and a composite of MACE, i.e. cardiac death, nonfatal myocardial infarction (MI) and non-MI-related target vessel revascularization (TVR). MACE including cause of death were adjudicated by an independent critical events committee blinded to the stent type used. Non-fatal MI was defined as typical symptoms with an elevation in cardiac enzymes, i.e. troponin I, troponin T or creatine phosphokinase above the upper limit, or typical ST changes in the electrocardiogram at the time of symptoms [30]. TVR was defined as a clinical event since control angiography was not allowed without symptoms or signs of ischemia. TVR related to MI was counted among MI events, differing from TVR not related to MI. Follow-up angiography was allowed only if clinically indicated to eliminate the possibility of angiography-driven TVR.

PCI was performed according to standard techniques with the final decision on the appropriate strategy left to the physician in charge. The use of distal embolic protection devices was not required in this study. Patients received a loading dose of 250-500 $\mathrm{mg}$ aspirin i.v. or p.o. and clopidogrel $300 \mathrm{mg}$ p.o. prior to PCI; the use of glycoprotein IIb/IIIa inhibitors was left to the discretion of the physician in charge but was mainly given in patients with acute coronary syndromes or suboptimal angioplasty results. After PCI, long-term statin therapy was prescribed in all patients, as well as a maintenance dual antiplatelet therapy with aspirin 100 $\mathrm{mg}$ and clopidogrel $75 \mathrm{mg}$ daily for 6 months, irrespective of the stent type used. Patients were advised to stop clopidogrel after 6 months, but to continue aspirin.

\section{Follow-Up}

After 6 and 18 months, patients presented at the outpatient clinic or were contacted by a questionnaire with specific questions regarding rehospitalizations, adverse events and drug therapy. Additional data were collected from primary care physicians, referring cardiologists or relatives when necessary. For the whole study, follow-up was complete in 823 (99.6\%) patients regarding survival and 813 (98.4\%) patients regarding all events.

\section{Statistical Analysis}

All analyses were performed by intention to treat, with the primary aim to compare patients with DES and BMS. Quantitative variables are presented as means \pm SD or medians \pm interquartile ranges, as appropriate. Categorical variables are described by their distribution. Two-group comparisons were done using the $\chi^{2}$ test or Fisher's exact test for categorical variables, where appropriate, and unpaired $t$ test for quantitative variables. 
Fig. 1. Patient-flow chart of the study population.

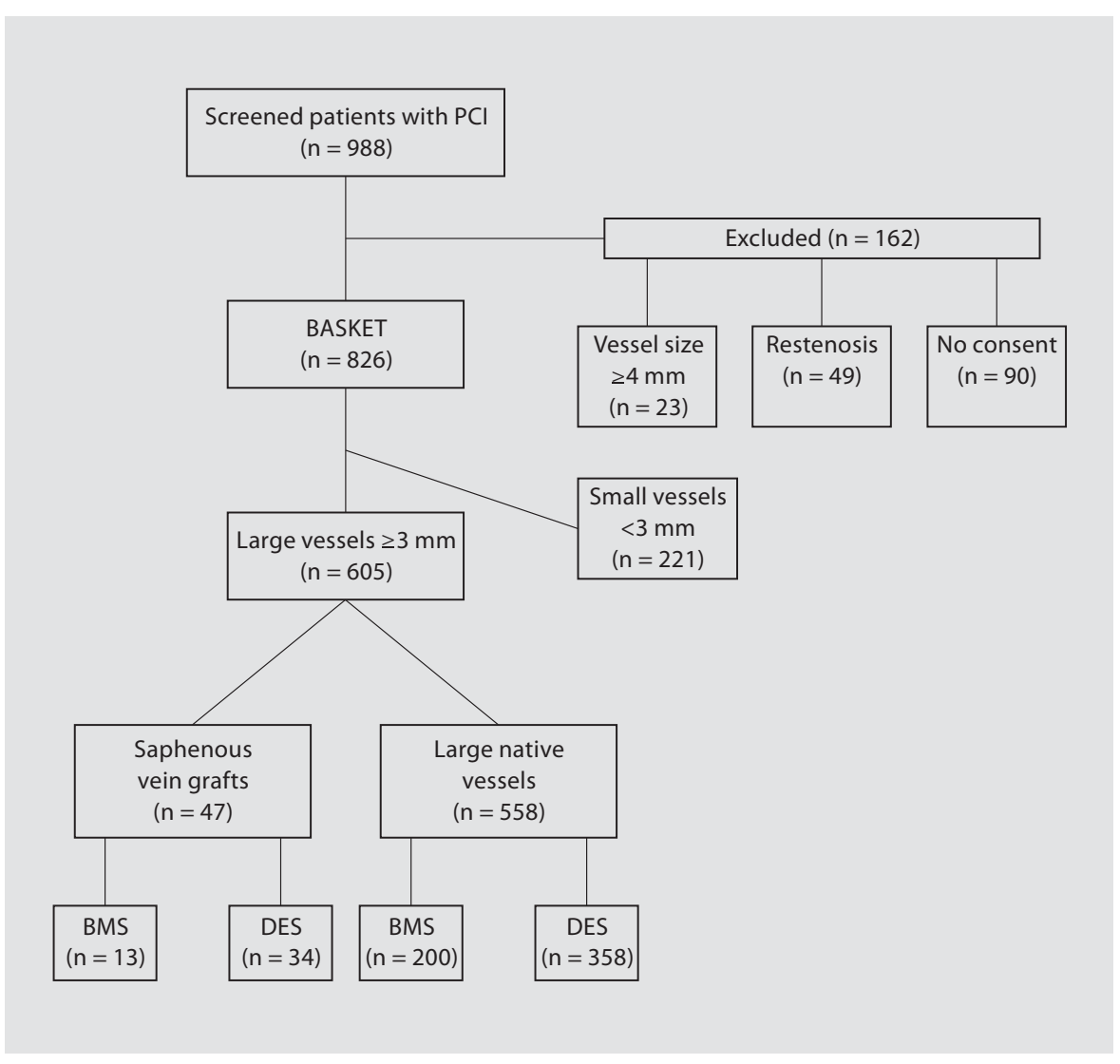

Kaplan-Meier curves were used for calculating time-dependent occurrence of events, and the log-rank test to compare the different groups. All p values were two-sided and considered statistically significant if $\mathrm{p}<0.05$. All calculations were performed with the use of a commercially available statistical package (SPSS 13.0, SPSS, Chicago, Ill., USA).

\section{Results}

\section{Patient Population}

Between May 2003 and May 2004, 988 patients underwent PCI, of whom $162(16 \%)$ had to be excluded due to a target vessel diameter $\geq 4 \mathrm{~mm}(\mathrm{n}=23)$, restenotic lesions $(\mathrm{n}=49)$ or no consent $(\mathrm{n}=90)$. Of note, most patients excluded due to a vessel diameter $>4 \mathrm{~mm}$ in fact had SVG disease; they could not be randomized because DES of this size were not available at the time of the study. In total, 826 patients were enrolled into BASKET, of whom $545(66 \%)$ received DES (Cypher, $\mathrm{n}=264$, and Taxus, $\mathrm{n}=281$ ), and 281 (34\%) BMS. Interventions in large vessels $\geq 3 \mathrm{~mm}$ were performed in 605 (73\%) patients (SVG interventions in $47,8 \%$, and large native ves- sel interventions in 558, 92\%). Of the patients undergoing PCI in SVG lesions, 34 (72\%) were treated with DES (Cypher, $\mathrm{n}=22$, and Taxus, $\mathrm{n}=12$ ), and $13(28 \%)$ with BMS (fig. 1).

\section{Patient Characteristics}

Patients undergoing SVG interventions were older and had more often hypertension, prior MI and prior PCI compared with patients with large native vessel lesions (table 1). In contrast, SVG patients were less frequently current smokers. Indication for PCI in SVG disease was less often acute ST-elevation MI and more often chronic angina compared with large native vessel disease. On average, patients with SVG lesions received more stents with a longer total length and a larger size than patients with large native vessel lesions.

Except for a somewhat longer stent length in DEStreated patients in large native vessel disease, baseline clinical and angiographic characteristics were similar among DES- and BMS-treated patients within the two groups (table 1). 
Fig. 2. Cumulative clinical outcome after 18 months in SVG (a) and large native vessels (b) for BMS vs. DES (Fisher's exact test or $\chi^{2}$ test where appropriate).

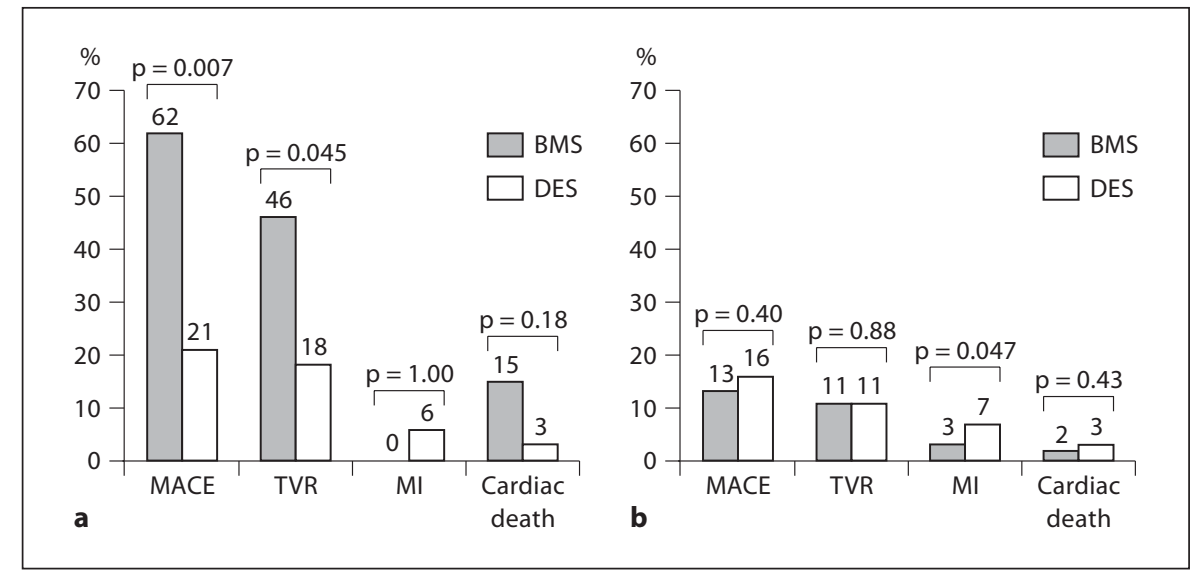

Table 1. Baseline clinical and angiographic characteristics

\begin{tabular}{|c|c|c|c|c|c|c|c|c|c|c|}
\hline & \multirow{2}{*}{$\begin{array}{l}\text { All } \\
(n=605)\end{array}$} & \multicolumn{4}{|c|}{ Bypass grafts } & \multicolumn{4}{|c|}{ Large native vessels } & \multirow[t]{2}{*}{$\mathrm{p}^{\mathrm{a}}$} \\
\hline & & $\begin{array}{l}\text { all } \\
(\mathrm{n}=47)\end{array}$ & $\begin{array}{l}\text { BMS } \\
(\mathrm{n}=13)\end{array}$ & $\begin{array}{l}\text { DES } \\
(\mathrm{n}=34)\end{array}$ & $\mathrm{p}^{\mathrm{b}}$ & $\begin{array}{l}\text { all } \\
(\mathrm{n}=558)\end{array}$ & $\begin{array}{l}\text { BMS } \\
(n=200)\end{array}$ & $\begin{array}{l}\text { DES } \\
(\mathrm{n}=358)\end{array}$ & $\mathrm{p}^{\mathrm{b}}$ & \\
\hline Age, years & $63 \pm 11$ & $71 \pm 8$ & $71 \pm 8$ & $71 \pm 8$ & 0.70 & $63 \pm 11$ & $63 \pm 11$ & $62 \pm 11$ & 0.61 & $<0.0001$ \\
\hline Females, \% & 22 & 15 & 0 & 21 & 0.076 & 22 & 20 & 23 & 0.38 & 0.25 \\
\hline Prior MI, \% & 25 & 55 & 46 & 59 & 0.44 & 23 & 24 & 22 & 0.55 & $<0.0001$ \\
\hline Prior PCI, \% & 16 & 43 & 39 & 44 & 0.73 & 14 & 14 & 14 & 0.99 & $<0.0001$ \\
\hline Prior CABG, \% & 13 & 100 & - & - & - & 6 & 7 & 5 & 0.42 & $<0.0001$ \\
\hline Diabetes, $\%$ & 18 & 26 & 17 & 29 & 0.39 & 17 & 17 & 18 & 0.72 & 0.14 \\
\hline Hypertension, \% & 65 & 87 & 83 & 88 & 0.67 & 63 & 64 & 63 & 0.83 & 0.001 \\
\hline Hypercholesterolemia, \% & 76 & 83 & 92 & 79 & 0.28 & 75 & 78 & 74 & 0.31 & 0.26 \\
\hline Current smoking, \% & 31 & 13 & 0 & 18 & 0.12 & 33 & 33 & 33 & 0.92 & 0.005 \\
\hline Multivessel disease, \% & 65 & 100 & - & - & - & 62 & 63 & 62 & 0.91 & $<0.0001$ \\
\hline Indication for PCI, \% & & & & & 0.11 & & & & 0.85 & 0.03 \\
\hline STEMI & 24 & 11 & 15 & 9 & & 25 & 15 & 9 & & \\
\hline Acute coronary syndrome & 36 & 34 & 54 & 27 & & 36 & 54 & 27 & & \\
\hline Chronic angina & 40 & 55 & 31 & 65 & & 39 & 31 & 65 & & \\
\hline GP IIb/IIIa inhibitors, \% & 28 & 28 & 46 & 21 & 0.08 & 28 & 26 & 29 & 0.44 & 0.97 \\
\hline Warfarin, \% & 7 & 5 & 0 & 7 & 0.37 & 7 & 6 & 7 & 0.61 & 0.60 \\
\hline Implanted stents, $\mathrm{n}$ & $1.7 \pm 1.0$ & $2.2 \pm 1.3$ & $2.4 \pm 1.5$ & $2.1 \pm 1.2$ & 0.48 & $1.7 \pm 0.9$ & $1.6 \pm 1.0$ & $1.7 \pm 0.9$ & 0.61 & $<0.0001$ \\
\hline$\geq 1$ stents, $\%$ & 30 & 49 & 62 & 44 & 0.29 & 28 & 26 & 29 & 0.44 & 0.002 \\
\hline DES, $\%$ & 65 & 72 & - & - & - & 64 & - & - & - & 0.34 \\
\hline Stent length, mm & $31 \pm 18$ & $42 \pm 26$ & $46 \pm 30$ & $41 \pm 25$ & 0.59 & $30 \pm 17$ & $28 \pm 16$ & $31 \pm 17$ & 0.05 & $<0.0001$ \\
\hline Stents $\geq 3.5 \mathrm{~mm}, \%$ & 35 & 49 & 17 & 29 & 0.39 & 34 & 33 & 34 & 0.71 & 0.033 \\
\hline
\end{tabular}

STEMI = ST elevation; GP = glycoprotein .

${ }^{a}$ Bypass grafts vs. large native vessels, $t$ test, Fisher's test, or $\chi^{2}$ test, where appropriate.

${ }^{b}$ BMS vs. DES, t test, Fisher's test, or $\chi^{2}$ test, where appropriate.

Outcome with DES versus BMS in SVG Lesions

Compared with Large Native Vessel Lesions

After 18 months, the incidence of MACE in patients with SVG disease was $62 \%$ in the BMS group compared with $21 \%$ in the DES group ( $p=0.007$, fig. $2 \mathrm{a}$ ). This dif- ference was mainly driven by a higher non-MI related TVR rate in BMS- versus DES-treated patients (46 vs. $18 \% ; \mathrm{p}=0.045)$, while MI and cardiac death rates were not different. In contrast, the 18-month outcome in large native vessel disease was similar with both stent types 
Fig. 3. Kaplan-Meier curves with log-rank test for survival without major adverse cardiac events in patients undergoing PCI on bypass grafts versus large native vessels using different types of stents.

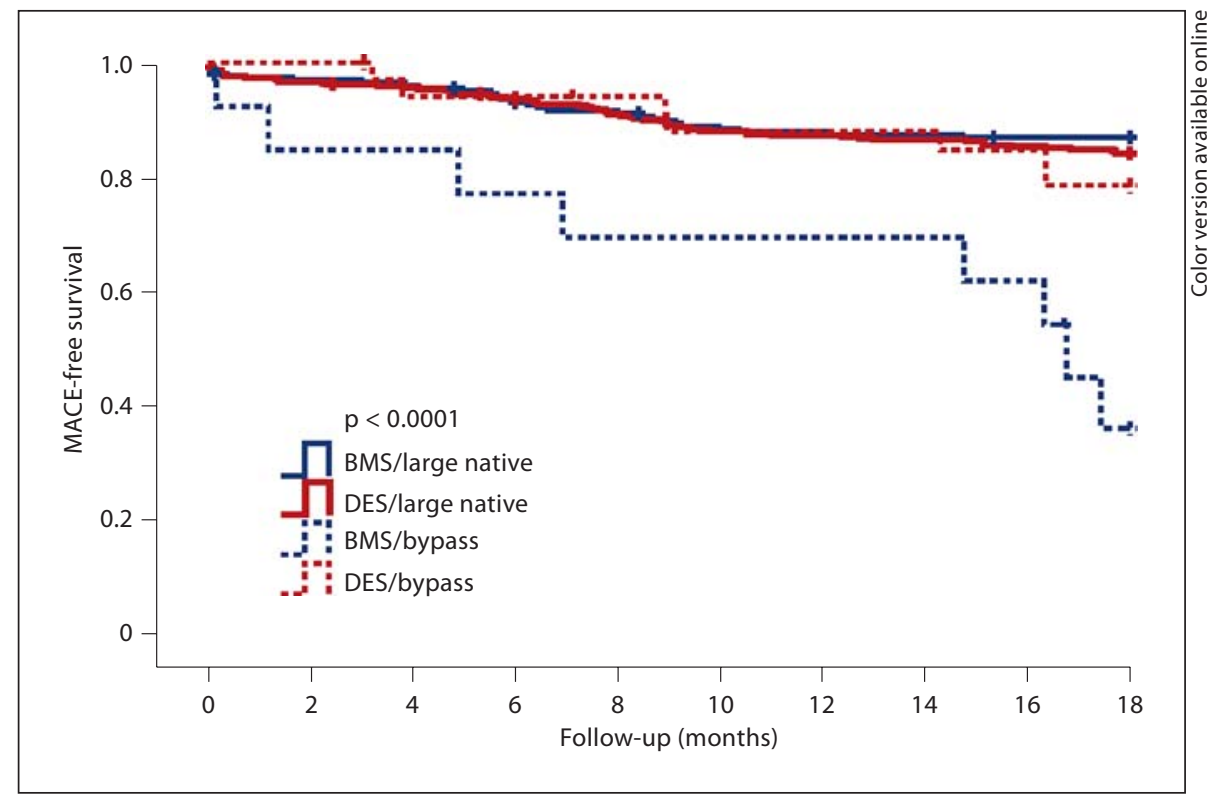

used without any difference in cardiac death or non-MIrelated TVR rates (fig. 2b). Of note, the numerically higher MACE rates were mostly due to higher rates of nonfatal MI in DES- versus BMS-treated patients during follow-up ( $\mathrm{p}=0.047$ ).

As depicted in figure 3, outcome between the four groups was statistically different $(\mathrm{p}<0.0001)$. This difference was mainly due to a much higher event rate in SVG lesions treated with BMS, whereas DES in SVG lesions and both stent types in large native vessel lesions had a similar efficacy in preventing MACE.

\section{Discussion}

The present results demonstrate a high recurrence rate of clinical events after PCI of SVG lesions. While the high event rate of SVG lesions treated with BMS was reduced to the event rate of large native vessel interventions by the use of DES, no such effect was seen in patients with lesions of native vessels of similar size.

In SVG, atherosclerosis with large, soft, friable plaques may develop early after CABG surgery due to surgical trauma, loss of intrinsic vascular supply and abrupt increase in wall stress $[12,17]$. Morphologic features of atherosclerotic SVG disease include concentric and diffuse changes, inflammatory infiltrates and absence of a fibrous cap [18]. This special pathophysiology may respond more favorably to antiproliferative and immunosuppres-

Drug-Eluting versus Bare Metal Stents sive effects of drugs used in DES. Therefore, the beneficial clinical effect of both paclitaxel and sirolimus in SVG lesions as shown in the present study might be due to their effect on concentric intimal hyperplasia and local inflammation.

Similar to previous studies [31, 32], the present analysis did not show any benefit of DES on outcome in large native vessel lesions. However, non-fatal MI rate was somewhat elevated in DES-treated patients with native large vessel interventions which might reflect an elevated rate of acute thrombotic stent occlusions, but this difference was small.

Data on the effect of DES in PCI of SVG lesions are conflicting. A previously published retrospective analysis showed a lower incidence of MACE in DES-treated patients after 6 months [24]. In another retrospective cohort study, the incidence of death, MI and TVR was lower in DES compared with BMS patients after a mean follow-up time of 9 months after SVG PCI [25]. Newer retrospective data show no significant difference in longterm outcome over a mean of 33 months with DES compared with BMS [33]. However, the recently published randomized RRISC study in patients undergoing SVG PCI showed a higher mortality rate for DES after 3 years of follow-up ( 29 vs. $0 \%$; p < 0.001) [27], although late loss was reduced by the use of a sirolimus-eluting DES after 6 months [26]. The significance of this result is unclear, since mid-term angiographic results and long-term clinical results were highly conflicting in this study. Con- 
trary to RRISC and in accordance to previous retrospective studies, our data support the notion that compared with BMS DES exert a long-term beneficial clinical effect on SVG interventions. However, large randomized trials with long-term follow-up are warranted to define the efficacy and safety of DES in SVG interventions.

\section{Limitations}

Since this is a predefined but retrospective secondary analysis of prospectively collected data, this study is in contrast to the prospective, randomized RRISC study. Therefore, the current analysis is subject to inherent limitations. This analysis was neither specifically randomized nor stratified for SVG disease, which may explain small imbalances between stent groups. Furthermore, the small sample size, specifically the small number of patients with BMS, and the follow-up duration of 18 months may preclude final conclusions. In addition, patients with a vessel diameter $\geq 4 \mathrm{~mm}$ were not included in this analysis due to the non-availability of adequately sized DES at the time of the study, which may have produced a selected SVG population with a smaller vessel size than expected. Since the exact TVR localization was not specified in this analysis, no conclusion can be drawn regarding the differentiation between in-stent restenoses and additional lesions. However, because stent length was not statistically different between DES and BMS in SVG lesions, rates of additional lesions causing events might be similar in both groups. Finally, the study was not powered to detect differences between the two DES used, but there was no difference in event rates between the two stents in the 18-month follow-up of the overall BASKET study [23]. These findings and limitations hold true for first-generation DES only, but data for newer DES are still lacking.

\section{Conclusions}

Patients with SVG lesions undergoing PCI have a worse outcome than patients with native vessel lesions of the same size. Among patients with SVG lesions, treatment with DES results in a reduced rate of MACE after 18 months, specifically TVR, compared with treatment with BMS, but no DES benefit was found in interventions in similarly sized native vessels regarding MACE. Therefore, these findings suggest that patients with SVG lesions undergoing PCI might best be treated with DES.

\section{References}

-1 Bourassa MG, Fisher LD, Campeau L, Gil lespie MJ, McConney M, Lesperance J: Longterm fate of bypass grafts: the Coronary Artery Surgery Study (CASS) and Montreal Heart Institute experiences. Circulation 1985;72:V71-V78.

-2 Morrison DA, Sethi G, Sacks J, Henderson W, Grover F, Sedlis S, Esposito R, Ramanathan KB, Weiman D, Talley JD, Saucedo J, Antakli T, Paramesh V, Pett S, Vernon S, Birjiniuk V, Welt F, Krucoff M, Wolfe W, Lucke JC, Mediratta S, Booth D, Barbiere C, Lewis D: Percutaneous coronary intervention versus coronary bypass graft surgery for patients with medically refractory myocardial ischemia and risk factors for adverse outcomes with bypass: the VA AWESOME multicenter registry: comparison with the randomized clinical trial. J Am Coll Cardiol 2002;39:266-273.

-3 de Feyter PJ, van Suylen RJ, de Jaegere PP, Topol EJ, Serruys PW: Balloon angioplasty for the treatment of lesions in saphenous vein bypass grafts. J Am Coll Cardiol 1993;21: 1539-1549.
4 Kahn JK, Rutherford BD, McConahay DR, Johnson W, Giorgi LV, Ligon R, Hartzler GO: Usefulness of angioplasty during acute myocardial infarction in patients with prior coronary artery bypass grafting. Am J Cardiol 1990;65:698-702.

5 Morrison DA, Crowley ST, Veerakul G, Barbiere CC, Grover F, Sacks J: Percutaneous transluminal angioplasty of saphenous vein grafts for medically refractory unstable angina. J Am Coll Cardiol 1994;23:10661070.

-6 Stone GW, Brodie BR, Griffin JJ, Grines L, Boura J, O’Neill WW, Grines CL: Clinical and angiographic outcomes in patients with previous coronary artery bypass graft surgery treated with primary balloon angioplasty for acute myocardial infarction. Second Primary Angioplasty in Myocardial Infarction Trial (PAMI-2) Investigators. J Am Coll Cardiol 2000;35:605-611.

$\checkmark 7$ de Jaegere PP, van Domburg RT, Feyter PJ, Ruygrok PN, van der Giessen WJ, van den Brand MJ, Serruys PW: Long-term clinical outcome after stent implantation in saphenous vein grafts. J Am Coll Cardiol 1996;28: 89-96.
8 Hanekamp CE, Koolen JJ, Den Heijer P Schalij MJ, Piek JJ, Bar FW, De Scheerder I, Bonnier HJ, Pijls NH: Randomized study to compare balloon angioplasty and elective stent implantation in venous bypass grafts: the Venestent study. Catheter Cardiovasc Interv 2003;60:452-457.

$\checkmark 9$ Keeley EC, Velez CA, O’Neill WW, Safian $\mathrm{RD}$ : Long-term clinical outcome and predictors of major adverse cardiac events after percutaneous interventions on saphenous vein grafts. I Am Coll Cardiol 2001;38:659_ 665.

10 Piana RN, Moscucci M, Cohen DJ, Kugelmass AD, Senerchia C, Kuntz RE, Baim DS, Carrozza JP Jr: Palmaz-Schatz stenting for treatment of focal vein graft stenosis: immediate results and long-term outcome. J Am Coll Cardiol 1994;23:1296-1304.

11 Savage MP, Douglas JS Jr, Fischman DL, Pepine CJ, King SB 3rd, Werner JA, Bailey SR, Overlie PA, Fenton SH, Brinker JA, Leon MB, Goldberg S: Stent placement compared with balloon angioplasty for obstructed coronary bypass grafts. Saphenous Vein De Novo Trial Investigators. N Engl J Med 1997; 337:740-747. 
12 Baim DS: Percutaneous treatment of saphenous vein graft disease: the ongoing challenge. J Am Coll Cardiol 2003;42:13701372.

-13 Baim DS, Wahr D, George B, Leon MB, Greenberg J, Cutlip DE, Kaya U, Popma JJ, Ho KK, Kuntz RE: Randomized trial of a distal embolic protection device during percutaneous intervention of saphenous vein aorto-coronary bypass grafts. Circulation 2002; 105:1285-1290.

14 Stone GW, Rogers C, Hermiller J, Feldman R, Hall P, Haber R, Masud A, Cambier P, Caputo RP, Turco M, Kovach R, Brodie B, Herrmann HC, Kuntz RE, Popma JJ, Ramee S, Cox DA: Randomized comparison of distal protection with a filter-based catheter and a balloon occlusion and aspiration system during percutaneous intervention of diseased saphenous vein aorto-coronary bypass grafts. Circulation 2003;108:548-553.

15 Kuntz RE, Baim DS, Cohen DJ, Popma JJ, Carrozza JP, Sharma S, McCormick DJ, Schmidt DA, Lansky AJ, Ho KK, Dandreo KJ, Setum CM, Ramee SR: A trial comparing rheolytic thrombectomy with intracoronary urokinase for coronary and vein graft thrombus (the Vein Graft AngioJet Study [VeGAS 2]). Am J Cardiol 2002;89:326-330.

16 Stone GW, Cox DA, Low R, Cates CU, Satler L, Bailey SR, Kuntz RE, Lansky AJ: Safety and efficacy of a novel device for treatment of thrombotic and atherosclerotic lesions in native coronary arteries and saphenous vein grafts: results from the multicenter X-Sizer for treatment of thrombus and atherosclerosis in coronary applications trial (X-TRACT) study. Catheter Cardiovasc Interv 2003;58: 419-427.

17 de Feyter PJ: Percutaneous treatment of saphenous vein bypass graft obstructions: a continuing obstinate problem. Circulation 2003;107:2284-2286.

18 Sarjeant JM, Rabinovitch M: Understanding and treating vein graft atherosclerosis. Cardiovasc Pathol 2002;11:263-271.
19 Colombo A, Drzewiecki J, Banning A, Grube E, Hauptmann K, Silber S, Dudek D, Fort S, Schiele F, Zmudka K, Guagliumi G, Russell ME: Randomized study to assess the effectiveness of slow- and moderate-release polymer-based paclitaxel-eluting stents for coronary artery lesions. Circulation 2003;108: 788-794.

20 Morice MC, Serruys PW, Sousa JE, Fajadet J, Ban Hayashi E, Perin M, Colombo A, Schuler G, Barragan P, Guagliumi G, Molnar F, Falotico R: A randomized comparison of a sirolimus-eluting stent with a standard stent for coronary revascularization. N Engl J Med 2002;346:1773-1780.

21 Moses JW, Leon MB, Popma JJ, Fitzgerald PJ, Holmes DR, O'Shaughnessy C, Caputo RP, Kereiakes DJ, Williams DO, Teirstein PS, Jaeger JL, Kuntz RE: Sirolimus-eluting stents versus standard stents in patients with stenosis in a native coronary artery. N Engl J Med 2003;349:1315-1323.

22 Stone GW, Ellis SG, Cox DA, Hermiller J, O’Shaughnessy C, Mann JT, Turco M, Caputo R, Bergin P, Greenberg J, Popma JJ, Russell ME: A polymer-based, paclitaxel-eluting stent in patients with coronary artery disease. N Engl J Med 2004;350:221-231.

23 Pfisterer M, Brunner-La Rocca HP, Buser PT, Rickenbacher P, Hunziker P, Mueller C, Jeger R, Bader F, Osswald S, Kaiser C, BASKET-LATE Investigators: Late clinical events after clopidogrel discontinuation may limit the benefit of drug-eluting stents: an observational study of drug-eluting versus baremetal stents. J Am Coll Cardiol 2006;48: 2584-2591.

24 Ge L, Iakovou I, Sangiorgi GM, Chieffo A, Melzi G, Cosgrave J, Montorfano M, Michev I, Airoldi F, Carlino M, Corvaja N, Colombo A: Treatment of saphenous vein graft lesions with drug-eluting stents: immediate and midterm outcome. J Am Coll Cardiol 2005; 45:989-994.

25 Lee MS, Shah AP, Aragon J, Jamali A, Dohad S, Kar S, Makkar RR: Drug-eluting stenting is superior to bare metal stenting in saphenous vein grafts. Catheter Cardiovasc Interv 2005;66:507-511.

26 Vermeersch P, Agostoni P, Verheye S, Van den Heuvel P, Convens C, Bruining N, Van den Branden F, Van Langenhove G: Randomized double-blind comparison of sirolimus-eluting stent versus bare-metal stent implantation in diseased saphenous vein grafts: six-month angiographic, intravascular ultrasound, and clinical follow-up of the RRISC Trial. J Am Coll Cardiol 2006;48: 2423-2431.
7 Vermeersch P, Agostoni P, Verheye S, Van den Heuvel P, Convens C, Van den Branden F, Van Langenhove G: Increased late mortality after sirolimus-eluting stents versus baremetal stents in diseased saphenous vein grafts: results from the randomized DELAYED RRISC Trial. J Am Coll Cardiol 2007;50:261-267.

28 Kaiser C, Brunner-La Rocca HP, Buser PT, Bonetti PO, Osswald S, Linka A, Bernheim A, Zutter A, Zellweger M, Grize L, Pfisterer ME: Incremental cost-effectiveness of drugeluting stents compared with a third-generation bare-metal stent in a real-world setting: randomised Basel Stent Kosten Effektivitäts Trial (BASKET). Lancet 2005;366:921-929.

29 Brunner-La Rocca HP, Kaiser C, Pfisterer M: Targeted stent use in clinical practice based on evidence from the Basel Stent Cost Effectiveness Trial (BASKET). Eur Heart J 2007; 28:719-725.

30 Myocardial infarction redefined - a consensus document of the Joint European Society of Cardiology/American College of Cardiology Committee for the redefinition of myocardial infarction. Eur Heart J 2000;21: 1502-1513.

-31 Pache J, Dibra A, Mehilli J, Dirschinger J, Schomig A, Kastrati A: Drug-eluting stents compared with thin-strut bare stents for the reduction of restenosis: a prospective, randomized trial. Eur Heart J 2005;26:12621268.

32 Quizhpe AR, Feres F, de Ribamar Costa J Jr, Abizaid A, Maldonado G, Costa R, Abizaid A, Cano M, Moreira AC, Staico R, Mattos LA, Tanajura LF, Chaves A, Centemero M, Sousa AM, Sousa JE: Drug-eluting stents vs bare metal stents for the treatment of large coronary vessels. Am Heart J 2007; 154:373378.

33 Bansal D, Muppidi R, Singla S, Sukhija R, Zarich S, Mehta JL, Sachdeva R: Percutaneous intervention on the saphenous vein bypass grafts - long-term outcomes. Catheter Cardiovasc Interv 2008;71:58-61. 